\title{
Modeling and Evaluating Spatial Variation of Pollution Characteristics in the Nyang River
}

\author{
Shouning Hao ${ }^{1}$, Yicheng $\mathrm{Fu}^{2 *}$, Jian Zhang ${ }^{2}$, Yanping $\mathrm{Zou}^{3}$, Jun Wei ${ }^{4}$, Heng Zheng ${ }^{4}$ \\ ${ }^{1}$ Tibet Agriculture and Animal Husbandry University, Nyingchi, 860000, China \\ ${ }^{2}$ China Institute of Water Resources and Hydropower Research, Beijing, 100038, China \\ ${ }^{3}$ Chongqing Jiaotong University, Chongqing, 400074, China \\ ${ }^{4}$ Power China Huadong Engineering Corporation Limited, Zhejiang Hangzhou 311122, China
}

Received: 2 January 2021

Accepted: 23 June 2021

\begin{abstract}
To understand the water quality status of the main stream of the Nyang River and the main pollution factors affecting the water body, surface water samples from 10 monitoring sections along the mainstream of the Nyang River were collected during the high-water (July-September) and low-water (January-March) seasons in 2018. Water quality indexes of chemical oxygen demand (COD), ammonia nitrogen $\left(\mathrm{NH}_{3}-\mathrm{N}\right)$, total nitrogen $(\mathrm{TN})$, total phosphorus (TP), $\mathrm{Pb}$ and $\mathrm{Cd}$ were selected for analysis. Water quality of the mainstream was then evaluated by single-factor assessment, comprehensive pollution index evaluate and principal component analysis. The results of single-factor evaluations show that COD is the main factor determining the type of water quality in the Nyang River, which belongs to Class III when COD is not included in the evaluation. The results of the comprehensive pollution index method show that the water quality of the Nyang River is relatively good as a whole. To clean the water body, more than $70 \%$ of the monitoring sections need to meet the Class II water quality standard. COD and TN are the main pollution factors of the main water body of the Nyang River. The results of principal component analysis (PCA) show that the water quality of the Nyang River is mainly affected by $\mathrm{NH}_{3}-\mathrm{N}, \mathrm{Pb}, \mathrm{Cd}, \mathrm{TP}$ and $\mathrm{COD}$, and that the area with the most severe pollution is the middle reaches of the river. The three methods are an organic combination of qualitative and quantitative evaluations, and the evaluation results were largely consistent between methods. Generally, the water quality in the high-water season of the Nyang River is better than that in the low-water season. However, there are many differences between the screening results of water pollution factors; therefore, a variety of important methods are used to analyse the main pollution factors of the water body.
\end{abstract}

Keywords: water quality, single-factor assessment, pollution index method, principal component analysis, Nyang River

*e-mail: swfyc@126.com 


\section{Introduction}

The Qinghai-Tibet Plateau is known as the "Asian Water Tower" and is the source of the top ten rivers in Asia. It is affected by the geology, landforms, high altitudes and unique climate of the region. The rivers in the Qinghai-Tibet Plateau are reticulated, the lakes are dotted, and the aquatic ecosystem is diverse. With the globally warming environment, the snow and ice melt and precipitation in the QinghaiTibet Plateau have changed, indirectly increasing river runoff and therefore affecting the characteristics of the river water environment $[1,2]$. In recent years, due to the socioeconomic development of the QinghaiTibet Plateau and the impact of human activities, the increase in pollutant emissions and the river pollutant concentration exceeds the standards of threshold for water quality, and, as a result, the aquatic environment of the plateau river has been seriously affected [3, 4]. The Nyang River Basin is located in the ecological security barrier zone in southeastern Tibet. The aquatic environment is fragile. At the same time, the Nyang River is an important drinking water source in Nyingchi City. The water quality directly affects drinking water safety for the residents of the riverbank. The development of crop farming, animal husbandry and tourism increased the total amount of water, as well as the discharge of non-point source pollutants from the river, which improves its water quality [5]. The threat to the Nyang River aquatic environment has become increasingly prominent. The issue of pollutant concentration is above the threshold in the Nyang River has become increasingly prominent as a constraint on the sustainable development of plateau cities. Due to various conditions and factors, very few researches focused on the water quality of the Nyang River. The research on the water quality only considers conventional indicators of water quality using the single-factor evaluation method and fuzzy synthesis. The evaluation methods applied in previous studies are too simplistic, there are few cases in which the water quality of the Nyang River has been comprehensively evaluated $[6,7]$.

To protect the water environment status of the main stream of the Nyang River and find the main pollution factors affecting the water body, ten monitoring sections in the Nyang River were used in this study for the collection and evaluation of surface water samples. The six water quality indicators tested were statistically analyzed during high- and low-water periods, and then the single-factor evaluation method, the comprehensive pollution index method and the principal component analysis method were used to qualitatively and quantitatively evaluate the river water pollution status and analyze the main pollutants in the Nyang River. These indicators provided a reference for the prevention of water pollution and inform sustainable development in the Nyang River.

\section{Materials and Methods}

\author{
Study Area
}

The Nyang River Basin is located in the northwest of Nyingchi City. The river originates from the defunct wood-processing pool pull on the west side of the Mila Mountain in the Tibet Autonomous Region. It merges into the Brahmaputra River near Nyingchi County and is the second largest tributary of the Brahmaputra. The Nyang River is affected by the Indian Oceans warm current and the northern cold current, forming unique climatic conditions in the Nyingchi region. The climate in the basin is mild and humid, with an average annual temperature of approximately $8^{\circ} \mathrm{C}$, annual precipitation of approximately $800 \mathrm{~mm}$ and annual diameter flow concentrated from June to September [8]. The runoff in the flood season accounts for approximately $90 \%$ of the total annual runoff $[9,10]$. The Nyang River is an important water source for agriculture and animal husbandry. The productivity of farmers and herdsmen in the basin, such as their livestock and poultry breeding and farming, has been affected by the water quality of different functional zones in the mainstream of the Nyang River. The water environment quality of the Nyang River plays an important role in regional socio-economic development and the improvement of ecological conditions.

\section{Sampling Points}

According to the principle of section layout in "Technical Specifications for Surface Water and Sewage Monitoring" (HJ/T 91-2002), combined with the unique topography and features of the plateau rivers and the distribution characteristics of the Nyang River system, comprehensive analysis of pollution sources and water conservancy projects in the basin was performed. Due to the distribution characteristics and accessibility of sampling points, a total of 10 monitoring sections are arranged in the mainstream of the river (see Fig. 1). The sampling frequency is once a month during the 2018 dry season (January-March) and the high-water period (July-September). Six evaluation indicators are selected: chemical oxygen demand (COD), ammonia nitrogen $\left(\mathrm{NH}_{3}-\mathrm{N}\right)$, total nitrogen $(\mathrm{TN})$, total phosphorus (TP), lead $(\mathrm{Pb})$ and cadmium $(\mathrm{Cd})$. Representative water quality indicators total nitrogen (TN), total phosphorus (TP), ammonia nitrogen $\left(\mathrm{NH}_{3}-\mathrm{N}\right)$, chemical oxygen demand (COD) was collected in the field and $500 \mathrm{ml}$ water samples are separately fixed with sulfuric acid and nitric acid, placed in a sealed sampling container belt, and returned to the laboratory for measurement (3 repetitions). Detection of lead $(\mathrm{Pb})$ and cadmium (Cd) is carried out with an SP-35620 atomic absorption spectrophotometer at the Institute of Plateau Water Environment and Water Ecology. The preservation, 


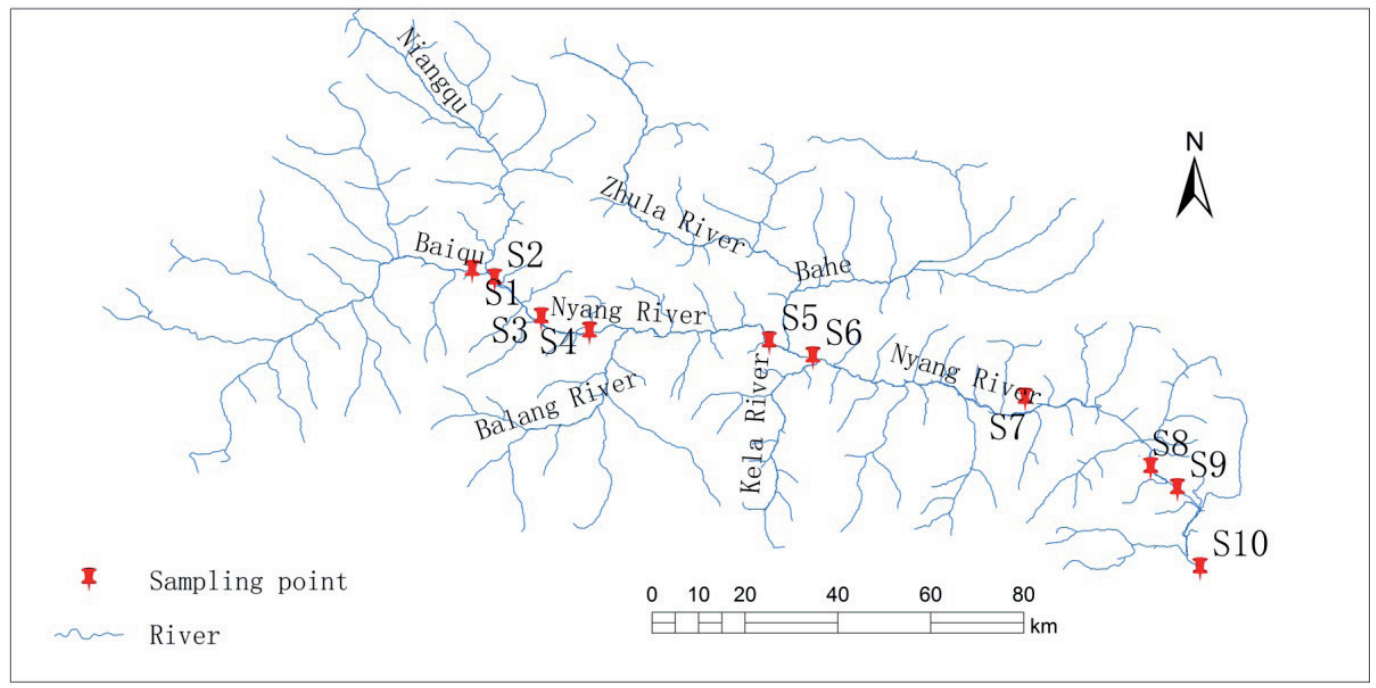

Fig. 1. Sampling sections in the Nyang River.

pretreatment and testing of water quality is strictly in accordance with relevant national standards.

\section{Data and Methodology}

To better compare the evaluation results of different evaluation methods in this study, six water quality indicators were selected for evaluation and analysis of the 10 monitoring sections using the single-factor evaluation method, the comprehensive pollution index method and the principal component analysis method. The results of each evaluation index for a given monitoring section are calculated as the average of the three parallel samples, and the error of each test result is controlled within 5\% [11]. The concentration of each indicator in the period of the flood season and the dry season of the monitoring section was obtained during the high-water period and the dry season, respectively. The data processing was performed in Excel 2007 and SPSS 23.0 software.

\section{Single-Factor Evaluation}

The single-factor evaluation method is based on the ratio of the measured value of the water quality index for the water body to the corresponding background or comparison value in the evaluation standard. When the index value is less than 1 , the water quality meets the standard requirement. Lower index values indicate better water quality, and vice versa. The one-factor evaluation method adopts a one-vote veto system where the water quality category of the monitoring section in the period is determined by the highest concentration index among the indicators measured, and, if one of the water quality indicators in the evaluation exceeds the standard, the evaluation result is exceeded. The evaluation formula is shown in Equations 1 and 2 [12]. Equation 2 is used when the background value is a range. The mainstream of the Nyang River provides the drinking water source of the towns along the banks, according to the standard "Class III Water Quality Standard Limits in the Surface Water Environmental Quality Standard Value" (GB3838-2002) [13].

$$
\begin{gathered}
I_{d}=\frac{C}{C_{0}} \\
I_{d}=\left|C-\bar{C}_{0}\right| /\left(\mathrm{C}_{0 \max }-\overline{\mathrm{C}}_{0}\right) \\
{ }_{\text {or }} I_{d}=\left|C-\bar{C}_{0}\right| /\left(\overline{\mathrm{C}}_{0}-\mathrm{C}_{0 \text { min }}\right)
\end{gathered}
$$

where $\boldsymbol{I}_{\boldsymbol{d}}$ is a single water quality index that identifies a polluted water body when $\boldsymbol{I}_{\boldsymbol{d}}>1$ and an uncontaminated water body when $\boldsymbol{I}_{\boldsymbol{d}}<1 . \boldsymbol{C}$ is the measured concentration value of a single pollutant index, $\boldsymbol{C}_{\mathbf{0}}$ is the corresponding background value or control value in the water quality standard, and $\boldsymbol{C}_{0 \max }$ and $\boldsymbol{C}_{0 \min }$ are the maximum and minimum values of the interval between the background value and the control value, respectively.

\section{Comprehensive Pollution Index Evaluation}

The comprehensive pollution index evaluation uses the ratio of the measured value of water quality index for a water body to the corresponding background or control value in the evaluation standard as the single pollution indicator, $\boldsymbol{P}_{i}$, and then obtains a comprehensive pollution indicator, $\boldsymbol{P}$, by equal weighting to evaluate the monitoring section. The classification criteria for water quality are shown in Table 1 . The main pollution indicators are identified by the pollution sharing rate, $\boldsymbol{K}_{\mathrm{i}}$, and are calculated as follows. 
Table 1. Grades of water quality according to comprehensive pollution index.

\begin{tabular}{|c|c|c|c|c|c|}
\hline Comprehensive pollution index & $\leq 0.25$ & $0.26 \sim 0.40$ & $0.41 \sim 0.50$ & $0.51 \sim 0.99$ & $\geq 1$ \\
\hline Water classification & I & II & III & IV & V \\
\hline
\end{tabular}

$$
\left\{\begin{array}{l}
P=\frac{\sum_{i=1}^{n} P_{i}}{n}=\frac{\sum_{i=1}^{n} \frac{C_{i}}{S_{i}}}{n} \\
K_{i}=\frac{P_{i}}{n P} \times 100 \%
\end{array}\right.
$$

discussed through the comprehensive score of water pollution in each monitoring section [17].

\section{Results and Discussion}

where $\boldsymbol{P}_{i}$ is the pollution index of the water body index $\boldsymbol{i}$, $C_{i}$ is the measured concentration value of the water body index $\boldsymbol{i}, \boldsymbol{S}_{\boldsymbol{i}}$ is the class III water quality standard limit of the water body index $\boldsymbol{i}$ in the table of the surface water environmental quality standard value (GB3838-2002), $\boldsymbol{n}$ is the number of water indicators in the section, $\boldsymbol{P}$ is the comprehensive water pollution index of the monitoring section, and $\boldsymbol{K}_{i}$ is the pollution sharing rate of the water index $\boldsymbol{i}$.

\section{Principal Component Analysis and Evaluation}

The principal component analysis method uses linear transformation to analyse a large number of complex water quality indicators and transforms them into a few independent indicators under the principle of ensuring minimal original data loss [14, 15], and, according to the transformation, these comprehensive indicators are used for the comprehensive analysis of water bodies. In this study, SPSS 23.0 software was used to standardize the water quality data before the principal component analysis of the six indicators of the two-stage water body [16] and then extract the main components of the water body index concentration of each monitoring section in the Nyang River. To make the meaning of each principal component clearer, this factor is rotated by the maximum variance method, and the evaluation is based on the obtained twirl factor load matrix. The water quality status is simultaneously

\section{Characteristics of Water Quality Indicators}

To understand the water quality of the Nyang River, the average values of the six water quality indicators during the wet and dry periods of the Nyang River mainstream were calculated and used for statistical analysis. The results are shown in Table 2.

\section{Nutrient Indicators}

It can be seen from Table 1 that the nutrient index of the Nyang River mainstream has a mean value of less than $0.5 \mathrm{mg} / \mathrm{L}$ in both the high-water period and the dry season (the surface water environmental quality standard value GB3838-2002 Class II water quality standard value), and the mean value ranges from $0.107 \sim 0.772 \mathrm{mg} / \mathrm{L}$ and $0.174 \sim 0.765 \mathrm{mg} / \mathrm{L}$. Forty percent of the monitoring sections concentration during the high water period are lower than $0.2 \mathrm{mg} / \mathrm{L}$ (Class I water quality standard value), and 50\% during the dry season. However, for all monitoring stations during the two periods, the cross-section water quality is beyond the Class III water quality standards; the mean value of $\mathrm{NH}_{3}-\mathrm{N}$ during the wet and dry seasons is less than $0.15 \mathrm{mg} / \mathrm{L}$, between $0.005 \sim 0.201 \mathrm{mg} / \mathrm{L}$ and $0.057 \sim 0.211 \mathrm{mg} / \mathrm{L}$, respectively. Among the two water quality test results during the different seasons, only the average $\mathrm{NH}_{3}-\mathrm{N}$ value of monitoring section $\mathrm{S} 1$ is greater than the Class III water quality standards, but both are lower than $0.5 \mathrm{mg} / \mathrm{L}$ (Class II water quality standard value). The average value of TP in the

Table 2. Statistical water quality data monitored in the Nyang River (mg/L).

\begin{tabular}{|c|c|c|c|c|c|c|c|}
\hline \multicolumn{2}{|c|}{ Water quality index } & $\mathrm{COD}$ & $\mathrm{TP}$ & $\mathrm{TN}$ & $\mathrm{NH}_{3}-\mathrm{N}$ & $\mathrm{Cd}$ & $\mathrm{Pb}$ \\
\hline \multirow{4}{*}{ Dry season } & Minimum & 8.74 & 0.007 & 0.174 & 0.057 & 0.00022 & 0.00114 \\
\cline { 2 - 8 } & Maximum & 63.43 & 0.015 & 0.765 & 0.211 & 0.00106 & 0.01653 \\
\cline { 2 - 8 } & Average & 19.974 & 0.0111 & 0.4225 & 0.0956 & 0.00061 & 0.005505 \\
\cline { 2 - 8 } & Standard deviation & 18.04846 & 0.002807 & 0.236276 & 0.044277 & 0.000262 & 0.004281 \\
\hline \multirow{3}{*}{ High water period } & Minimum & 6.43 & 0.003 & 0.107 & 0.005 & 0.00018 & 0.00314 \\
\cline { 2 - 8 } & Maximum & 61.92 & 0.018 & 0.772 & 0.201 & 0.00186 & 0.01612 \\
\cline { 2 - 8 } & Average & 23.729 & 0.0075 & 0.3857 & 0.0763 & 0.000626 & 0.005486 \\
\cline { 2 - 8 } & Standard deviation & 19.48622 & 0.004378 & 0.262311 & 0.056052 & 0.000461 & 0.003872 \\
\hline
\end{tabular}


two-stage water body is less than $0.02 \mathrm{mg} / \mathrm{L}$ (Class I water quality standard value), and the mean value ranges are $0.003 \sim 0.018 \mathrm{mg} / \mathrm{L}$ and $0.007 \sim 0.015 \mathrm{mg} / \mathrm{L}$ between the wet and dry seasons, respectively. The TP content in the Nyang River water body is of higher quality than that of Class I water quality standard value during the wet and dry seasons. The water quality monitoring section reached $90 \%$. The results of the three types of nutrient indicators in the high-water period show that the average concentrations are lower than the found during the dry season, and the variations between the monitoring sections in the high-water period are larger than those during the dry season.

\section{Heavy Metals and Organic Pollution Indicators}

The average COD content in the Nyang River is lower than $20 \mathrm{mg} / \mathrm{L}$ (Class III water quality standard value), but the average value of $60 \%$ of all monitoring sections is classified as having higher water quality value than the standard value of Class I $(20 \mathrm{mg} / \mathrm{L})$ is below the Class IV water quality standard value $(30 \mathrm{mg} / \mathrm{L})$. The same highest COD content in the dry season appears in sections S5 and S6 which are both higher than $40 \mathrm{mg} / \mathrm{L}$ (Class $\mathrm{V}$ water quality standard value). The fluctuations in the range of COD detected in each monitoring section of the two-stage water body are relatively large, and the concentration values follow the same law in spatial distribution, but the overall trend is that the average concentration of the high-water period is greater than that of the dry season. The average content of the heavy metal index for $\mathrm{Pb}$ in the high-water period and dry season is lower than $0.01 \mathrm{mg} / \mathrm{L}$ (Class I water quality standard value), and the mean range varies between $0.003 \sim 0.0161 \mathrm{mg} / \mathrm{L}$ and $0.001 \sim 0.0165 \mathrm{mg} / \mathrm{L}$, respectively. The $30 \%$ of the monitoring sections are classified as Class I water bodies, and the monitoring section with the highest $\mathrm{Pb}$ content appears in section $\mathrm{S} 1$ at the same time, but the mean and fluctuation range of $\mathrm{Pb}$ concentrations in the high-water period are lower than that of the dry season. The average $\mathrm{Cd}$ content in the two-stage water body is less than $0.001 \mathrm{mg} / \mathrm{L}$ (Class I water quality standard value). The same two-stage test results show that $90 \%$ of the monitoring sections are higher than the Class I water quality standard values, and the water body has the highest $\mathrm{Cd}$ content. The monitoring section appears in section $\mathrm{S} 1$ at the same time. The Cd content fluctuation in the Nyang River monitoring sections during the flood season is higher than that during the dry season, and the overarching result is that the average concentration in the high-water period is greater than that in the dry season.

The overall performance of the Nyang River water body is as follows: the average concentrations of COD and $\mathrm{Cd}$ in the high-water period are higher than those in the dry season, and the average concentrations of other water quality indicators are, similarly, lower in the wet season than those in the dry season. This pattern can be attributed to snow melting off the mountains and running into the basin. This sudden increase in flooding, due to abundant rainfall during the flood season and alpine snow melt water, increases the water volume of the river, thus increasing the dilution factor of the river water into the river pollutants. Excluding fluctuations in the concentration range of $\mathrm{Pb}$, the concentrations of water quality indicators during the dry season are greater than those during flood season, and range of the other five water quality indicators fluctuates less than that of the flood season. The water quality of the Nyang River in the flood season varies greatly spatially. The amount of non-point source pollutants carried in the river is inseparable. The spatial variation in the concentration values of the six water quality indicators is consistent with the results of the Nyang River water quality test preformed by Ciren Zhuoma [18].

\section{Single-Factor Model Evaluation Result}

The single-factor evaluation method was used to evaluate the water quality categories of the sampling sections of the Nyang River. When the organic pollution index, COD, was not considered into the evaluation, the water quality of the Nyang River water body during the wet and dry seasons are of Class III water quality. The results of the monitoring sections show that the water quality classification level of the two phases depends on the nutrient salt index for $\mathrm{TN}$. When the organic pollution index for COD is included in the evaluation, the water quality category of the Nyang River degrades.

According to the evaluation of the two water periods of the Nyang River, when the COD is excluded from evaluation, $100 \%$ of the monitoring sections reach Class III water quality, which fully guarantees drinking water safety for the residents on both sides of the Nyang River. When COD is included in the evaluation, monitoring sections S5 and S6 during the wet season show too low water quality to be classified under Class $\mathrm{V}$, but monitoring stations S1 and S3 were still that of the Class V water quality. Only $50 \%$ of the monitored sections were classified as Class III water quality, and the same lower Class V water quality still applied to sections S5 and S6. These results suggest that COD has a great influence on the water quality of the mainstream water in the Nyang River during the wet season and the dry season, and TN has lesser influence on the water quality assessment category of the mainstream.

\section{Comprehensive Pollution Index Evaluation Result}

The comprehensive pollution index method was used to calculate the comprehensive pollution index, $\boldsymbol{P}$, of the 10 monitoring sections of the Nyang River mainstream during the different seasons, and the contribution rate of for each of the six water indicators detected in each section was analyzed and compared. The results are shown in Table 3. The contribution rate of the six water indicators in each section is shown in Fig. 2. 
Table 3. Comprehensive pollution index in sampling sections of the Nyang River.

\begin{tabular}{|c|c|c|c|c|c|c|c|c|c|c|}
\hline Sampling section & S1 & S2 & S3 & S4 & S5 & S6 & S7 & S8 & S9 & S10 \\
\hline Dry season $\boldsymbol{P}$ & 0.40 & 0.31 & 0.39 & 0.27 & 0.49 & 0.66 & 0.15 & 0.17 & 0.17 & 0.14 \\
\hline High water period $\boldsymbol{P}$ & 0.50 & 0.27 & 0.38 & 0.39 & 0.68 & 0.41 & 0.14 & 0.13 & 0.12 & 0.14 \\
\hline
\end{tabular}

Based on the results of the comprehensive pollution index in Table 3, the overall trend of the water quality in the Nyang River mainstream appears to be essentially the same in the wet season and the dry season: the monitoring section with the highest comprehensive pollution index are sections S5 and S6 but during different seasons. The difference in the comprehensive pollution index between sections is larger, therefore, the spatial and temporal differences of the water quality in the mainstream of the Nyang River are more obvious. The results of Table 3 and Table 1 show that the comprehensive pollution index of $80 \%$ of the monitoring sections during the dry season is less than 0.41 , suggesting that the water body is relatively clean and reaches the Class II water quality standard, and the comprehensive pollution index of the 10 monitoring sections is between 0.14 and 0.66 . In section S6, the comprehensive pollution index reaches 0.66 and the pollution is the most extreme of all sections with a water quality classification of Class IV. Section S7 has the lowest comprehensive pollution index at 0.15 (the water body cleaning belongs to the Class I water quality standard). The comprehensive pollution index of these monitoring sections is between 0.12 and 0.68 , with fluctuation range that is larger than that of the dry season. The section with the lowest water quality is section S5 with a comprehensive pollution index of 0.68 (for moderate pollution and belongs to Class IV water quality standard). The section with the least pollution is section S9, whose comprehensive pollution index is only 0.12 . According to the quality of the twostage water body classification, the water quality of the Nyang River is generally adequate. The polluted water body mainly appears in the middle reaches (sections S5 and S6). Fluctuations in the comprehensive pollution index of each monitoring section during the flood season are larger than that of the dry season. The water quality during the wet season is better than the dry season when considering the existing research results and the conditions of the study area. The difference between the water quality during the wet season and the dry season is likely due to the changes in water volume caused by the rainfall in the basin and the Nyang River mainstream hydraulic structure. The amount of water in the mainstream causes the capacity of the water body's own water environment to decrease, which reduces the ability for self-dilution. The comprehensive pollution index evaluation results of the Nyang River monitoring sections are consistent with the non-point source pollution distribution in the basin.

The pollution comprehensive pollution index of each monitoring section can only indicate the water pollution status of the section but lacks ability to provide information on the pollution indicator contribution. The pollution sharing rate of each indicator in each section supplements the pollution status information of each indicator, as shown in Fig. 2. Fig. 2 shows that the contribution rate of the six water body indicators is essentially the same in the two-stage water body. The pollution sharing rate of $\mathrm{COD}$ and $\mathrm{TN}$ indicators is significantly higher than other indicators studied. The single pollution index of COD in the dry season is $0.44 \sim 3.17$ and the single pollution index in the wet season ranges from $0.38 \sim 3.10$, where the pollution sharing rate in both phases exceeds $30 \%$. TN has a single pollution index ranging from 0.11 to 0.77 in the two phases; the pollution sharing rate in the highwater period is up to $47 \%$, and the pollution sharing rate in each section in the dry season is in the range of $12 \%$ to $41 \%$. The water body index with the lowest pollution sharing rate in the two-stage water body is TP, where the highest value in each section is less than $6 \%$.
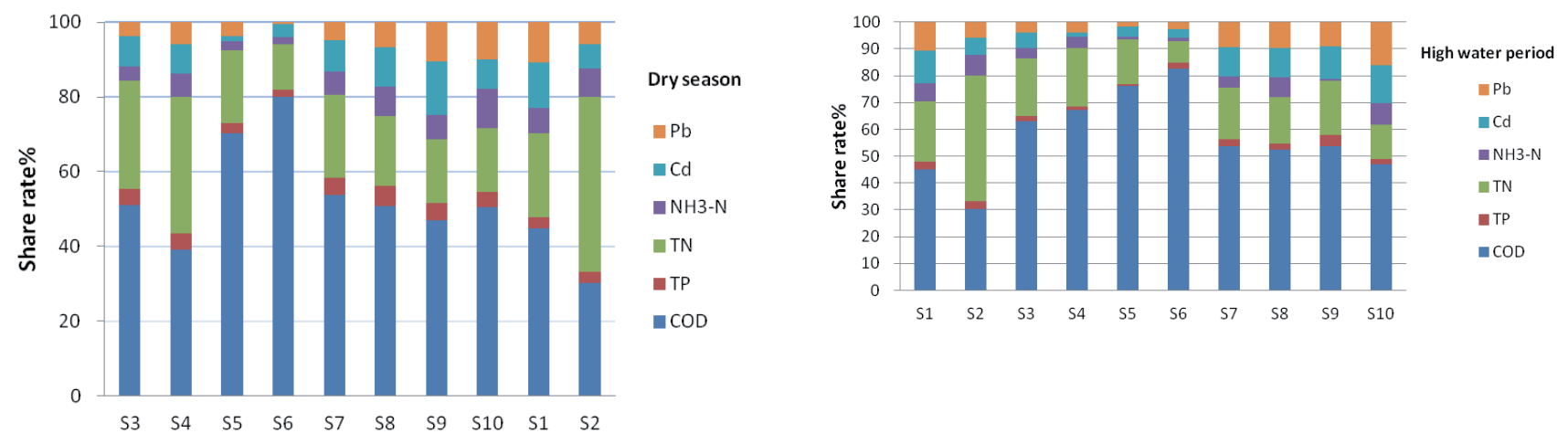

Fig. 2. Percentage of pollutants in sampling sections of the Nyang River. 
The sum of COD and TN in all sections is greater than $60 \%$, suggesting that the two water indicators, COD and $\mathrm{TN}$, have a substantial influence on the water quality in the Nyang River.

\section{Principal Component Analysis and Evaluation Result}

The KMO and Bartleet test results for each monitoring section during each season were analysed by SPSS23.0. The KMO test values of the two groups of data in the wet and dry seasons were 0.548 and 0.501 , respectively (both greater than 0.5 ), and the significance of the Bartleet test was 0.000 and 0.001 (both less than 0.01 ), respectively. The results of this analysis indicate that the principal component analysis of the data for both seasons is feasible [14]. The main component extraction and rotation factor loading matrix results of the water quality indicators for the 10 monitoring are shown in Table 4. The number of principal components selected in the principal component analysis method is based on the cumulative contribution rate greater than $80 \%$. The Nyang River water body index extracted two main components during the wet season, and the cumulative variance contribution rate of FPC1 and FPC2 reached $84.7 \%$. The variance contribution rate of FPC1 was $59.33 \%$, which was much larger than other principal component contribution rates. The main component has a great influence on water quality. At the same time, the related factors are mainly $\mathrm{NH}_{3}-\mathrm{N}, \mathrm{Pb}$ and $\mathrm{Cd}$. The absolute value of the load is greater than 0.90 . The absolute value of the COD load in FPC2 is greater than 0.90 in the Nyang River water during the wet period. The heavy metal indexes $\mathrm{NH}_{3}-\mathrm{N}, \mathrm{Pb}, \mathrm{Cd}$ and $\mathrm{COD}$ have a high impact on water quality. Two main components are also extracted during the dry season; the cumulative variance contribution rate of LPC1 and LPC2 reaches $81.997 \%$, and the absolute value of the dry load during loading is greater than $0.90 . \mathrm{NH}_{3}-\mathrm{N}, \mathrm{Pb}$ and $\mathrm{TP}$ are the most important factors affecting water quality during the dry season.
The comprehensive scores of the monitoring sections of the two phases of the Nyang River mainstream are calculated as the principal component comprehensive model by using the ratio of the eigenvalues corresponding to each principal component to the sum of the total eigenvalues of the extracted principal components. The comprehensive principal component values of each section are calculated according to the principal component comprehensive model (where a higher score indicates lower water quality). A negative score does not represent a negative correlation, but, rather, indicates that the composite score is lower than the average. The main components of the Nyang River monitoring sections in the wet and dry seasons are shown in Table 5. The results show that the distribution of contamination of the 10 monitoring sections in the mainstream of the Nyang River varies in time and space. The distribution of water quality in the two phases throughout the whole basin is similar in spatial distribution. The monitoring sections with the highest comprehensive scores in the wet and dry seasons are sections S5 and S6 (located in the middle reaches of the mainstream). It is worth noting that the comprehensive score of section S5 in the wet season is higher than that of section S6, while the comprehensive score of section S5 in the dry season is lower than that of section S6. This result shows that the water quality of the Bahe River is better than that of the mainstream of the Nyang River during the wet period, while the water volume of the Bahe River is relatively low during the dry season. Due to the influence of agriculture and animal husbandry in the Ba River Basin, the water quality of the Bahe River is lower than that of the Nyang River. The lowest water quality monitoring sections are S9 and S10 (belonging to the downstream of the mainstream).

The overall score results suggest that the Nyang River water quality in the high-water period is better than that of the dry season, and that the pollution in the middle reaches of the mainstream is the most severe. The economic development of the upper reaches of the Nyang River is slow, and the middle reaches is

Table 4. Rotated component matrix of principal component analysis

\begin{tabular}{|c|c|c|c|c|}
\hline \multirow{2}{*}{ Index } & \multicolumn{2}{|c|}{ High water period } & \multicolumn{2}{c|}{ Dry season } \\
\cline { 2 - 5 } & FPC1 & FPC2 & LPC1 & 0.803 \\
\hline COD & -0.052 & 0.933 & -0.198 & 0.946 \\
\hline TP & 0.840 & 0.331 & 0.113 & 0.674 \\
\hline TN & 0.506 & 0.707 & 0.630 & -0.072 \\
\hline $\mathrm{NH3-N}$ & 0.907 & 0.156 & 0.961 & 0.242 \\
\hline $\mathrm{Cd}$ & 0.911 & 0.126 & 0.761 & -0.167 \\
\hline $\mathrm{Pb}$ & 0.970 & -0.049 & 0.940 & 34.743 \\
\hline Contribution \% & 59.330 & 25.370 & 47.254 & 87.997 \\
\hline
\end{tabular}


Table 5. Assessment results of sampling sections in the Nyang River.

\begin{tabular}{|c|c|c|c|c|}
\hline \multirow{2}{*}{ Sampling section } & \multicolumn{2}{|c|}{ High water period } & \multicolumn{2}{c|}{ Dry season } \\
\cline { 2 - 5 } & Composite score & Comprehensive ranking & Composite score & Comprehensive ranking \\
\hline S1 & 2.197 & 5 & 1.702 & 3 \\
\hline S2 & 0.887 & 6 & 1.239 & 5 \\
\hline S3 & 2.241 & 4 & 1.286 & 6 \\
\hline S4 & 2.459 & 3 & 1.198 & 2 \\
\hline S5 & 4.825 & 1 & 3.633 & 1 \\
\hline S6 & 3.152 & 2 & 5.465 & 0.858 \\
\hline S7 & 0.735 & 7 & 0.924 & 7 \\
\hline S8 & 0.672 & 8 & 0.857 & 9 \\
\hline
\end{tabular}

the densely populated Gongbujiangda County. A small amount of domestic sewage flows into the Niyang River, so the water quality of the middle reaches is poor. The water quality of each monitoring section of the Niyang River is relatively good. However, with the rapid economic and social development, domestic wastewater is continuously discharged into the Niyang River, resulting in poor water quality during the dry season. According to the results of principal component analysis, $\mathrm{NH}_{3}-\mathrm{N}, \mathrm{Pb}, \mathrm{Cd}$ and $\mathrm{COD}$ in the water during the flood season have the greatest influence on the water quality. Unlike the flood season, $\mathrm{NH}_{3}-\mathrm{N}, \mathrm{Pb}$ and $\mathrm{TP}$ in the water have the greatest influence on the water quality during the dry season.

\section{Comparison of Three Methods}

The single-factor evaluation method determines the water quality category from the worst indicator and can qualitatively evaluate the water quality of each monitoring section of the Nyang River to determine the water quality category. However, it is not possible to rank the different monitoring sections of the same type of water quality in greater detail. Both the comprehensive pollution index method and the principal component analysis method can quantitatively evaluate the water quality of the mainstream of the Nyang River. These methods can simultaneously adequately classify the water pollution status of each monitoring section in detail. The three methods show the same water quality results for the 10 monitoring sections of the two phases of the Nyang River mainstream flow, with the sections showing the most substantial water pollution in the two phases being sections S5 and S6. However, there are certain differences in the identification of major pollution factors in the mainstream waters of the Nyang River: The comprehensive pollution index method indicated similar results as the single-factor evaluation method. The main factors affecting the water quality of the two phases are COD and TN. The principal component analysis method, based on the cumulative contribution rate of variance as the factor weight identification results, shows that the main influencing factors of water quality in the wet season are $\mathrm{NH}_{3}-\mathrm{N}, \mathrm{Pb}, \mathrm{Cd}$ and $\mathrm{COD}$ and $\mathrm{NH}_{3}-\mathrm{N}, \mathrm{Pb}$ and $\mathrm{TP}$ in the dry season. There are specified differences in the identification of major pollution indicators by the three methods. This is because the principal component analysis method identifies the pollution factor based on the cumulative contribution rate of the variance as the factor weight. The comprehensive pollution index method does not consider the factor weight effect and only adopts the equal weight treatment. The single-factor evaluation method directly considers each item when it intuitively recognizes the concentration value of the indicator. Each of the three evaluation methods has their own advantages and disadvantages, reflecting the high-risk water quality indicators in the mainstream waters of the Nyang River from different perspectives.

\section{Conclusions}

COD is the main limiting factor for the water quality of the Nyang River. When the COD was not involved in the evaluation, the water quality of the two phases reached the Class III water quality standard. When the COD was evaluated, only $50 \%$ to $60 \%$ of the water in the monitoring section were classified under the Class III water quality standard, and the water quality of other sections did not meet the requirements of the drinking water quality standard.

The comprehensive pollution index of the 10 monitoring sections of the Nyang River mainstream in the wet and dry seasons ranged from 0.12 to 0.68 
and 0.14 to 0.66 , respectively. $70 \%$ and $80 \%$ of the monitoring sections in the wet and dry seasons, respectively, met the Class II water quality standards. The water quality of the mainstream of the Nyang River is mainly affected by the COD and TN indicators. The sum of the COD and TN pollution sharing rates in the water bodies of the two water periods is greater than $60 \%$. The COD single pollution index varies from 0.38 to 3.17 , and the $\mathrm{TN}$ single pollution index ranges from 0.11 to 0.77 .

Principal component analysis shows that the water quality of the Nyang River was mainly affected by $\mathrm{NH}_{3}-\mathrm{N}, \mathrm{Pb}, \mathrm{Cd}$ and $\mathrm{COD}$ indicators, while the dry season was affected by $\mathrm{NH}_{3}-\mathrm{N}, \mathrm{Pb}$ and $\mathrm{TP}$ indicators. The results of the 10 monitoring sections are as follows: In general, the water quality during the wet season is higher than that of the dry season in sections with the most water pollution in the midstream.

The three evaluation methods for the 10 monitoring sections of the mainstream of the Nyang River are consistent. The most polluted sections are S5 and S6. However, there are significant differences in the identification of pollution factors by the three evaluation methods. Compared with the single-factor evaluation method, the comprehensive pollution index method and principal component analysis method can quantitatively provide more water quality information for each evaluation monitoring section. This benefit compensates for the pros and cons of single-factor evaluation, making the water quality evaluation results of the Nyang River mainstream more objective.

\section{Acknowledgments}

The study was financially supported by National Key Research and Development Program of China (2016YFC0401408, 2016YFC0401606), Comprehensive Regulation Theory and Application of Basin Water Environment Process (WE0145B532017), and Major Science and Technology Program for Water Pollution Control and Treatment (2018ZX07105002). The author appreciates all the participants and anonymous reviewers for their valuable comments and criticisms.

\section{Conflict of Interest}

The authors declare no conflict of interest.

\section{References}

1. PEPIN N., BRADLEY R.S., DIAZ H.F. Elevationdependent warming in mountain regions of the world. Nature Climate Change 5, 424, 2015.

2. LIU H.P., ZHONG G.H., YE S.W. Multivariate statistical analysis of water environment for Niyang River, the branch of the Yarlung Zangbo River, Tibet. Journal of Lake Sciences 27, 1187, 2015.

3. LI Z.J., ZHENG Y.X., ZHANG D.W., NI J.B. Impacts of 20-year socio-economic development on aquatic environment of Lake Dianchi Basin. Journal of Lake Sciences 24, 875, 2012.

4. HAO S.N., ZONG Y.C., DONG F. Using GIS to Analyze Spatial Distribution of Contaminants Emanating from Nonpoint Pollution Source in Nyang River Basin. Journal of Irrigation and Drainage 37, 106, 2018.

5. HAO S.N., FU Y.C. Spatio-temporal changes and distribution characteristics of pollutant loads from agricultural non-point sources in Nyingchi, Tibet. Journal of Agro-Environment Science, 36, 1308, 2017.

6. LA BACIREN, BU D., TAN X. Concentration and Risk Assessment of Metal Elements in Nyang River. The Administration and Technique of Environmental Monitoring, 29, 33, 2017.

7. MENG J.L., GUO J.Y., WU J. Seasonal variations of chemical weathering and its controlling factors of Nyang River in the Tibetan Plateau. Journal of Earth Environment, 11,190, 2020.

8. JIN H.Y., JU Q., YU, Z.B., HAO J., GU H.H., GU H.N., LI W. Simulation of snowmelt runoff and sensitivity analysis in the Nyang River Basin, southeastern Qinghai-Tibetan Plateau, China. Natural hazards 99, 931, 2019.

9. ZHANG T., CAI W.T., LI Y.Z., ZHANG Z.Y., GENG T.T., BIAN C. Major Ionic Features and Their Possible Controls in the Water of the Nyang River Basin. Environmental Science 38, 4537, 2017.

10. RAN G.H., WANG J., DAN Z. Analysis of the Normal Distribution of Precipitation in Linzhi Distric. Journal of Anhui Agri 41, 6403, 2013.

11. ZHU Y.Y., TIAN J.J., LI H.L., JIANG Q.F., LIU YAN. Water quality assessment and pollution profile identification of Danjiangkou Reservoir, China. Journal of Agro-Environment Science 35, 139, 2016.

12. GUO J., WANG C.M., HUANG D.Z., LI L.Q., LIAN H. Pollution characterization and water quality assessment of Dongting Lake. Environmental Chemistry 38, 152, 2019.

13. STATE ENVIRONMENTAL PROTECTION ADMINISTRATION. GB3838-2002 Surface water environmental quality standards. China Environmental Science Press. 2002.

14. ZHAO J., XU Z.X., LIU X.C., NIU C.J. Source apportionment in the Liao River Basin. China Environmental Science 33, 838, 2013.

15. WANG L.J., WANG X., LIU L.S., ZHENG B.H., LI L.Q., HUANG D.Z. Multivariate Analysis of Water Factors in Dongting Lake. Research of Environmental Sciences 26, 1,2013

16. PENG T., ZHOU L.N., LIU N. Application of principal component analysis with SPSS in water quality assessment of Shenzhen Eastern Beach. Agricultural Science and Technology 15, 688, 2014.

17. SINGH K.P., MALIK A., KUMAR R., SAXENA P., SINHA S. Receptor modeling for source apportionment of polycyclic aromatic hydrocarbons in urban atmosphere. Environmental Monitoring and Assessment 136, 183, 2008.

18. CI REN Z.M. Temporal and spatial characteristics of water quality in Nyang River, Tibet. Rural economy and technology 28, 20, 2017. 